\title{
Rotational isomers of lactic acid: first experimental observation of higher energy forms $\dagger$
}

\author{
Ana Borba, ${ }^{a}$ Andrea Gómez-Zavaglia, ${ }^{a b}$ Leszek Lapinski ${ }^{c}$ and R. Fausto ${ }^{* a}$ \\ a Department of Chemistry, University of Coimbra, P-3004-535, Portugal. \\ E-mail: rfausto@ci.uc.pt \\ ${ }^{b}$ Facultad de Farmacia y Bioquímica, Universidad de Buenos Aires, RA-1113, Argentina \\ c Institute of Physics, Polish Academy of Science Warsaw, PL-02-668, Poland
}

Received 19th December 2003, Accepted 25th February 2004

First published as an Advance Article on the web 26th March 2004

\begin{abstract}
Lactic acid $\left\{2\right.$-hydroxypropionic acid $\left.\left[\mathrm{CH}\left(\mathrm{CH}_{3}\right) \mathrm{OHCOOH}\right]\right\}$ monomer was studied by matrix isolation FT-IR spectroscopy and molecular orbital calculations undertaken at both DFT(B3LYP)/6-311++G(d,p) and MP2/ 6-31G $(\mathrm{d}, \mathrm{p})$ levels of approximation. The theoretical calculations predicted the conformer $(\mathrm{Ss} C)$ with the carboxylic group and both the $\mathrm{CCOH}_{\text {(alcohol) }}$ and $\mathrm{O}=\mathrm{CCO}$ moieties in a cis configuration as the most stable form. In this conformer, the $\alpha$-hydroxy hydrogen atom is involved in an intramolecular hydrogen bond with the carbonyl oxygen atom. The second most stable conformer $(G s k C)$ also shows a cis carboxylic group and differs from $S s C$ in the $\mathrm{CCOH}_{(\text {alcohol })}$ and $\mathrm{O}=\mathrm{CCO}$ dihedral angles, which are equal to $43.3^{\circ}$ and $156.8^{\circ}$ respectively. These angles are equal to $-51.5^{\circ}$ and $-149.9^{\circ}$ in the third most stable conformer $\left(G^{\prime} s k^{\prime} C\right)$. These forms are characterized by showing a relatively weak intramolecular $\mathrm{H}_{(\text {alcohol })} \cdots \mathrm{O}_{\text {(acid) }}$ hydrogen bond. In the AaT conformer, the carboxylic group is trans and the $\mathrm{CCOH}_{(\text {alcohol })}$ and $\mathrm{O}=\mathrm{CCO}$ dihedral angles are $162.2^{\circ}$ and $174.1^{\circ}$, respectively. This conformer shows a relatively strong $\mathrm{H}_{(\text {acid })} \cdots \mathrm{O}_{\text {(alcohol })}$ hydrogen bond. In consonance with the theoretical results, the matrix isolation experiments confirmed the predominance of conformer $S s C$ in argon and xenon matrices, and provide the first experimental evidence of conformers $G s k C$ and $A a T$. Since the barrier for interconversion $G^{\prime} s k^{\prime} C \leftrightarrow G s k C$ is only $\sim 2 \mathrm{~kJ} \mathrm{~mol}^{-1}$, these two conformers are in equilibrium in the matrices and, at low temperature, the population of the less stable $G^{\prime} s k^{\prime} C$ form is too small to enable its observation. Full assignment of the observed spectra was undertaken on the basis of comparison with the theoretical data and temperature variation studies. Water doping of matrices enabled the identification of spectral features due to weakly bound complexes of lactic acid with water.
\end{abstract}

\section{Introduction}

The biological importance of lactic acid is mainly due to its function as metabolite. Lactic acid is the main final product of lactic acid bacteria (LAB) metabolism and it is also produced as a result of anaerobic metabolism of glucose in eukaryotic cells. LAB have relatively simple carbon and energy metabolisms where the sugar source (lactose) is converted mainly to lactic acid. ${ }^{1}$ Polymer derivatives of lactic acid have also relevant practical applications, because their biodegradability to non-toxic products has important advantages for medicinal applications in surgical sutures, grafts, prosthetic devices, implants and drug delivery systems. ${ }^{2}$

The enzyme catalyzed processes involving lactic acid were found to be quite sensitive to stereochemical factors, with specific enzymes for production of each one of the two enantiomeric forms of the compound. ${ }^{3}$ This is mainly dependent upon the enzyme-substrate interactions within the enzyme's active site, where H-bond interactions can be devised to play a major role. On the other hand, these interactions can be predicted to depend, at least partially, on the conformation assumed by the substrate. For this reason, a deep insight into the conformational preferences of lactic acid and its vibrational properties appears essential to shed some light on the biochemical processes.

$\dagger$ Electronic supplementary information (ESI) available: optimised geometries, and calculated and observed frequencies and intensities. See http://www.rsc.org/suppdata/cp/b3/b316642b/
From a chemical point of view, lactic acid belongs to the family of $\alpha$-hydroxy acids, whose simplest member is glycolic acid. This latter compound is by far the most studied member of the family, both experimentally and theoretically. ${ }^{4-11}$ From 1977 to the present, several calculations have been carried out on glycolic acid at several levels of approximation, indicating that its most stable conformer is the intramolecularly hydrogen bonded form showing all the HOCC, $\mathrm{O}=\mathrm{CCO}$ and $\mathrm{O}=\mathrm{COH}$ angles equal to $0^{\circ}\left(S S C ;^{4,9,12}\right)$.

The microwave spectra of glycolic acid in the gaseous phase have been studied by Hasegawa et al. ${ }^{13}$ and Blom and Bauder. ${ }^{14}$ Hasegawa et al. have analyzed the microwave spectra of six iso topic species including $\mathrm{D}$ and ${ }^{18} \mathrm{O}$ isotopologues demonstrating unequivocally that the glycolic acid conformational ground state has both a planar skeleton and a five-membered hydrogen bonded ring type. ${ }^{13}$ The complete molecular structure of glycolic acid was also determined by Blom and Bauder ${ }^{14}$ This structure corresponds to the $S s C$ form described above. ${ }^{14}$

Matrix isolation IR spectroscopy studies on several isotopologues of glycolic acid have shown that in argon matrices the most stable conformer is the $S s C$ form. ${ }^{10,11}$ This conformer was also found by X-ray analyses to be the constituting molecular unit in the crystalline phase. ${ }^{5,6}$ However, in spite of the fact that the $S s C$ conformer is the most stable form in both the gas phase and the crystal, some of the geometrical parameters were found to be different under these two experimental conditions due to strong intermolecular hydrogen bonds in the solid state. ${ }^{14}$

The analogous dimethyl substituted derivative of glycolic

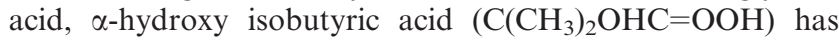


also been studied previously, both experimentally and theoretically. ${ }^{14}$ DFT(B3LYP)/6-311G(d,p) calculations predicted that the $S s C$ conformer should also correspond to the most stable form in this molecule. Accordingly, infrared spectroscopic data for the monomer isolated in argon, krypton and xenon matrices ${ }^{15}$ clearly showed that the $S s C$ conformer is the preferred conformational state of $\alpha$-hydroxy isobutyric acid. X-Ray structural studies as well as Raman and infrared data for the crystalline phase of this compound are in agreement with these results. ${ }^{15,16}$

Lactic acid differs from both glycolic and $\alpha$-hydroxy isobutyric acids because it is an optically active molecule. The structure of crystalline $\mathrm{L}-(+)$-lactic acid at $100 \mathrm{~K}$ was determined by Shouten et al. ${ }^{17}$ using X-ray diffraction. In that study it was found that, in the crystal, the molecule of lactic acid shows a quasi-planar $\mathrm{HOC}-\mathrm{COOH}$ molecular skeleton, with the oxygen atom of the aliphatic hydroxyl group at the side of the carbonyl oxygen atom. The two hydroxyl groups are involved in intermolecular hydrogen bonding: the aliphatic hydroxyl group forms a bifurcate planar hydrogen-bond in which the aliphatic hydroxyl and carbonyl oxygen atoms of a symmetry-related molecule participate as acceptors; the acidic hydroxyl group donates an intermolecular hydrogen bond to the aliphatic hydroxyl group oxygen atom of a neighboring molecule.

IR and Raman spectra of the compound in aqueous solution, where the compound was in its anionic form (carboxylate), were also reported previously and vibrational assignments for these spectra proposed by Cassanas et al. ${ }^{18,19}$

The microwave spectrum of lactic acid in the gaseous phase has been studied with aid of double resonance techniques. ${ }^{20}$ Selective deuteration in the two hydroxyl groups led to the conclusion that the conformation displaying a hydrogen bond from the $\alpha$-hydroxyl group to the carbonyl oxygen atom, analogous to the conformational ground state of both glycolic and $\alpha$-hydroxy isobutyric acids, is the most stable form of lactic acid in the gaseous phase. No evidence could be found in the microwave studies of the presence of other conformers in the gaseous phase.

Theoretical calculations on lactic acid have been undertaken by Pecul et al. ${ }^{21}$ In that work, ab initio calculations carried out at the SCF and MP2 levels, with the Dunning's standard augcc-pVDZ basis set on carbon and oxygen and cc-pVDZ on the hydrogen atoms, have been used. However, these authors postulated the existence of only two minima of low energy and a priori discarded all other possible structures. To the best of our knowledge, no further structural or conformational studies have been undertaken on lactic acid, and no vibrational studies on the monomeric species have been reported hitherto.

In this work, a systematic search on the possible minima on the Potential Energies Surface (PES) of monomeric lactic acid was performed at both the DFT and MP2 levels of theory. Matrix isolation FT-IR spectroscopy enabled us to observe, for the first time, higher energy conformers of the studied compound, and perform their vibrational characterization.

\section{Materials and methods \\ Computational methodology}

The quantum chemical calculations were performed with Gaussian $98^{22}$ at the DFT and MP2 levels of theory, using the $6-311++\mathrm{G}(\mathrm{d}, \mathrm{p})$ and $6-31++\mathrm{G}(\mathrm{d}, \mathrm{p})$ basis sets, respectively. ${ }^{23}$ The DFT calculations were carried out with the three-parameter density functional abbreviated as B3LYP, which includes Becke's gradient exchange correction ${ }^{24}$ and the Lee, Yang and Parr ${ }^{25}$ and Vosko, Wilk and Nusair correlation functionals. ${ }^{26}$

Conformations were optimized using the Geometry Direct Inversion of the Invariant Subspace (GDIIS) method. ${ }^{27}$
Vibrational frequencies were calculated at each level of theory and the nature of the stationary points on the potential energy surface resulting from optimization was determined by inspection of the corresponding calculated Hessian matrix. The optimized structures of all conformers were confirmed to correspond to true minimum energy conformations on the PES. The calculated frequencies were scaled down by a single factor (0.978) to correct them for the effects of basis set limitations, neglected part of electron correlation and anharmonicity effects, and used to assist the analysis of the experimental spectra. Normal coordinate analyses were undertaken in the internal coordinates space as described by Schachtschneider, ${ }^{28}$ using the program BALGA and the optimized geometries and harmonic force constants resulting from the DFT(B3LYP) $/ 6-311++\mathrm{G}(\mathrm{d}, \mathrm{p})$ calculations. Potential energy profiles for internal rotation were calculated performing a relaxed scan on the PES along the relevant reaction coordinates, and the transition state structures for conformational interconversion obtained using the Synchronous Transit-Guided Quasi-Newton (STQN) method. ${ }^{29}$

\section{Infrared spectroscopy}

L-(+)-Lactic acid was obtained from Aldrich (purity 99\%). The IR spectra were collected, with $0.5 \mathrm{~cm}^{-1}$ spectral resolution, on a Mattson (Infinity 60AR Series) Fourier Transform infrared spectrometer, equipped with a deuterated triglycine sulfate (DTGS) detector and $\mathrm{Ge} / \mathrm{KBr}$ beamsplitter.

In the matrix isolation experiments, a glass vacuum system and standard manometric procedures were used to deposit the matrix gas (argon, 99.99990\%; xenon, 99.995\%, obtained from Air Liquide). Matrices were prepared by co-deposition, onto the cooled CsI substrate of the cryostat, of the matrix gas (Ar or Xe), water dopant (whenever used) and lactic acid placed in a specially designed doubly thermostatable Knudsen cell with shut-off possibility whose main component is a NUPRO SS-4BMRG needle valve. The temperature of the cell can be controlled separately in the valve nozzle and the sample compartment, enabling a more precise control of the saturated gas pressure over the solid lactic acid and a better metering function of the valve. Further details of the experimental set up can be found elsewhere. ${ }^{30}$

All experiments were done on the basis of an APD Cryogenics close-cycle helium refrigeration system with a DE202A expander. Deposition temperatures used range from 9 to $20 \mathrm{~K}$. Necessary modifications of the sample compartment of the spectrometer were made in order to accommodate the cryostat head and allow efficient purging of the instrument by a stream of dry air to remove water and $\mathrm{CO}_{2}$ vapours. After depositing the compound, annealing experiments were performed until a temperature of $40 \mathrm{~K}$ and $60 \mathrm{~K}$, for $\mathrm{Ar}$ and $\mathrm{Xe}$, respectively.

\section{Results and discussion}

\section{Geometries and energies}

Lactic acid has three different internal rotation axes that can give rise to conformational isomers $\left(\mathrm{O}=\mathrm{COH} ; \mathrm{CCOH}_{(\text {alcohol })}\right.$; $\mathrm{O}=\mathrm{CCO}$ ). All possible conformers belong to the $C_{1}$ symmetry point group. Lactic acid has a chiral carbon which leads to the existence of enantiomers. $\ddagger$

As far as spectroscopy neglecting dichroic effects is concerned, chirality of lactic acid does not represent a source of

$\ddagger$ The following systematic rules were used to attribute names to the conformers: $\mathrm{O}=\mathrm{CCO}$ is indicated by the first letter $\left(S=\operatorname{syn}, 0^{\circ}\right.$; $A=$ anti,$\quad 180^{\circ} ; G=$ gauche, ca. $-60^{\circ} ; G^{\prime}=$ gauche, ca. $\left.60^{\circ}\right)$; $\mathrm{CCOH}_{(\text {alcohol })}$ is indicated by the second letter $\left(s=\operatorname{syn}, 0^{\circ} ; \mathrm{a}=a n t i\right.$, $180^{\circ} ;$ sk $=$ skew, $c a .-120^{\circ} ;$ sk $^{\prime}=$ skew $\left.^{\prime}, c a .120^{\circ}\right)$ and $\mathrm{O}=\mathrm{COH}$ is represented by the third letter $\left(C=\mathrm{s}-c i s, 0^{\circ} ; T=\mathrm{s}\right.$-trans, $\left.180^{\circ}\right)$. 
complications, because the spectra of both enantiomers are identical.

In this work, a full conformational search on both the DFT(B3LYP) $/ 6-311++\mathrm{G}(\mathrm{d}, \mathrm{p})$ and MP2/6-31++G(d,p) potential energy surfaces of lactic acid was undertaken. Table 1 presents the calculated relative energies for the possible conformers of lactic acid. The conformers are depicted in Fig. 1.

In consonance with the available microwave spectroscopy data ${ }^{20}$ and previous calculations, ${ }^{21}$ the theoretical calculations predict conformer $S S C$ as being the conformational ground state. This conformer is defined by $\mathrm{O}=\mathrm{COH}, \mathrm{CCOH}_{\text {(alcohol) }}$ and $\mathrm{O}=\mathrm{CCO}$ dihedral angles equal to $-0.2^{\circ}, 0.3^{\circ}$ and $-3.0^{\circ}$ respectively. As already mentioned, this form is similar to the most stable conformer of glycolic and $\alpha$-hydroxy isobutyric acids, being stabilized by an intramolecular $\mathrm{H}$-bond established between the $\mathrm{OH}$ alcohol group and the carbonyl oxygen atom.

The second most stable conformer (GskC in Fig. 1) is predicted to have $\mathrm{O}=\mathrm{COH}, \mathrm{CCOH}_{\text {(alcohol) }}$ and $\mathrm{O}=\mathrm{CCO}$ dihedral angles equal to $-0.3^{\circ} ; 43.3^{\circ}$ and $156.8^{\circ}$, respectively (DFT values are provided here; MP2 angles are shown in Table S1 $(\mathrm{ESI} \dagger))$. This form is characterized by a $\mathrm{OH}_{(\text {alcohol })} \cdots \mathrm{O}$ intramolecular H-bond. The third most stable conformer is $G^{\prime} s k^{\prime} C$, which differs from the previous one in the $\mathrm{CCOH}_{(\text {alcohol })}$ and $\mathrm{O}=\mathrm{CCO}$ dihedral angles which, in this case, are $-51.5^{\circ}$ and $-149.9^{\circ}$, respectively. This form has also a $\mathrm{OH}_{(\text {alcohol })} \cdots \mathrm{O}$ intramolecular $\mathrm{H}$-bond, but, in this case, the distance $\mathrm{H}_{\text {(alcohol) }} \cdots \mathrm{O}(230.6 \mathrm{pm})$ is larger than in $G s k C(221.9 \mathrm{pm})$, indicating that the $\mathrm{H}$-bond is weaker and justifying the slightly higher energy of the $G^{\prime} s k^{\prime} C$ conformer when compared to GskC. In conformer AaT (see Fig. 1), the calculated (DFT) values for the above mentioned dihedral angles are: $\mathrm{O}=\mathrm{COH}:-179.3^{\circ} ; \mathrm{CCOH}_{(\text {alcohol })}: 162.2^{\circ} \mathrm{O}=\mathrm{CCO}: 174.1^{\circ}$. This conformer shows a $\mathrm{OH}_{(\text {acid })} \cdots \mathrm{O}_{(\text {alcohol })} \mathrm{H}$-bond, which is relatively strong, and the carboxylic group in the energetically less favorable trans geometry.

Conformers $G s k C, G^{\prime} s k^{\prime} C$ and $A a T$ are predicted by the DFT calculation to be $8.00,8.55$ and $9.97 \mathrm{~kJ} \mathrm{~mol}^{-1}$ (MP2: $6.45,7.09$ and $11.38 \mathrm{~kJ} \mathrm{~mol}^{-1}$ ) higher in energy than the conformational ground state. This means that, at room temperature $(298.15 \mathrm{~K})$, the predicted populations for the three most stable conformers, taking into account the DFT calculated energies are 91.7, 3.6, 2.9 and 1.6\%, respectively (considering all possible conformers) (Table 1). The remaining conformers have a total population of $c a .0 .1 \%$ and can be considered of no practical importance. $\S$

Table 1 Relative energies, including zero point vibrational contributions for the various conformers of lactic $\mathrm{acid}^{a}$

\begin{tabular}{llll}
\hline & $\begin{array}{l}\mathrm{DFT}(\mathrm{B} 3 \mathrm{LYP}) / \\
6-311++\mathrm{G}(\mathrm{d}, \mathrm{p}) \\
\text { Conformer }\end{array}$ & $\begin{array}{l}\mathrm{MP} 2 / \\
6-31++\mathrm{G}(\mathrm{d}, \mathrm{p}) \\
E_{\mathrm{ZPE}}\end{array}$ & $\begin{array}{l}\text { Population } \\
(298 \mathrm{~K})^{c}\end{array}$ \\
\hline$S s C$ & $0.0(-902216.02)^{d}$ & $0.0(-899494.14)^{d}$ & $91.7 \%$ \\
$G s k C$ & 8.00 & 6.45 & $3.6 \%$ \\
$G^{\prime} s k^{\prime} C$ & 8.55 & 7.09 & $2.9 \%$ \\
$A a T$ & 9.97 & 11.38 & $1.6 \%$ \\
$A s C$ & 19.32 & 18.49 & $0.0 \%$ \\
$A a C$ & 19.33 & 18.64 & $0.0 \%$ \\
$S s T$ & 21.74 & 24.44 & $0.0 \%$
\end{tabular}

${ }^{a}$ Energies in $\mathrm{kJ} \mathrm{mol}^{-1}$; conformers are depicted in Fig. 1. ${ }^{b}$ Zero point energy corrections taken from DFT(B3LYP) $/ 6-311++\mathrm{G}(\mathrm{d}, \mathrm{p})$ calculations. ${ }^{c}$ Estimated using relative energies optimized at the DFT(B3LYP) level. ${ }^{d}$ Total energies with zero point vibrational energy contribution.

$\S$ Using MP2 relative energies, The estimated populations at room

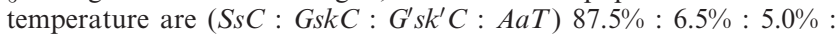
$0.9 \%$.
The calculated structural parameters for the four most stable conformers are provided in Table S1. In spite of the fact that all these conformers display intramolecular H-bonds, the atoms involved in these interactions in each form are different, and this is reflected in the relative values of their $\mathrm{OH}$ bond lengths. Conformer AaT is the only one that does not have the $\mathrm{H}_{\text {(alcohol) }}$ involved in a $\mathrm{H}$-bond. For this reason, the $\mathrm{O}$ $\mathrm{H}_{(\text {alcohol })}$ distance is shorter in this form $(96.2 \mathrm{pm}$ for $A a T$, $96.4 \mathrm{pm}$ for $G s k C$ and $G^{\prime} s k^{\prime} C$ and $96.8 \mathrm{pm}$ for $S s C$ ). This distance is larger in $S s C$ in comparison with both $G s k C$ and $G^{\prime} s k^{\prime} C$, indicating a stronger $\mathrm{H}$-bond in $S s C$, which also correlates well with the shorter $\mathrm{H}_{(\text {alcohol })} \cdots \mathrm{O}$ distance found for this conformer: $2.10 \mathrm{pm}$, vs. $2.23 \mathrm{pm}$ in $G s k C$ and $2.31 \mathrm{pm}$ in $G^{\prime} s k^{\prime} C$. In contrast, conformer $A a T$ is the only conformer having the $\mathrm{H}_{\text {(acid) }}$ involved in a $\mathrm{H}$-bond and, thus, has the largest O- $\mathrm{H}_{\text {(acid) }}$ distance: $97.3 \mathrm{pm}$, vs. $96.9 \mathrm{pm}$ for $G s k C$ and $G^{\prime} s k^{\prime} C$, and $97.0 \mathrm{pm}$ for $S s C$.

Table S1 (ESI $\dagger$ ) also enables the comparison of the geometrical parameters calculated in this work for conformer $S s C$ with the available X-ray data. The general agreement of the two sources of data can be considered fairly good, with the expected exceptions of the most sensitive parameters related to the atoms involved in $\mathrm{H}$-bonds (e.g. $\mathrm{O}-\mathrm{H}$ distances). The $\mathrm{O}-\mathrm{H}$ distances are normally shortened in crystals due to the strong intermolecular hydrogen bonds usually present in the solid state. It should also be mentioned that the molecules present in the crystalline phase differ from the $S s C$ conformer in the value of the $\mathrm{C}-\mathrm{C}-\mathrm{O}-\mathrm{H}$ dihedral angle: $-142.6^{\circ}$ in the crystal $^{17}$ vs. $0.3^{\circ}$ in $S s C$. This change is also related with the intermolecular interactions present in the crystal, enabling the $\mathrm{H}$ from the $\mathrm{OH}_{(\text {alcohol })}$ group to remain disposable to form an intermolecular $\mathrm{H}$-bond with a neighbor molecule, instead of the intramolecular $\mathrm{H}$-bond with the carbonyl atom.

Since internal rotations around the $\mathrm{C}-\mathrm{C}$ and $\mathrm{C}-\mathrm{O}_{\text {(alcohol) }}$ bonds allow the interconversion between all the cis conformers, an effort was made to calculate the energies of all the possible transition states interconnecting these conformers. Fig. 2 depicts a "cartesian" map with axes corresponding to the $\mathrm{O}=\mathrm{C}-\mathrm{C}-\mathrm{O}$ and $\mathrm{C}-\mathrm{C}-\mathrm{O}-\mathrm{H}_{(\text {alcohol })}$ dihedral angles, where the minima and transition states (TSn) were located. Four main pathways for conformational interconversion can be identified in this map, two corresponding essentially to changes in the conformation around the $\mathrm{C}_{\alpha}-\mathrm{C}$ bond, and two to the rotation around the $\mathrm{C}-\mathrm{O}_{\text {(alcohol) }}$ bond. Rotation around the $\mathrm{C}-\mathrm{C}$ bond defines the $S s C \stackrel{\mathrm{TS1}}{\longleftrightarrow} G^{\prime} s k^{\prime} C \stackrel{\mathrm{TS2}}{\longleftrightarrow} G s C \stackrel{\mathrm{TS3}}{\longleftrightarrow} S s C$ as well as the $A a C \stackrel{\text { TS8 }}{\longleftrightarrow} A s C$ paths. The interconversions $S s C \leftrightarrow G s k C$ and $S s C \leftrightarrow G^{\prime} s k^{\prime} C$ can also take place directly through transition states TS10 and TS9, respectively. Rotation around the $\mathrm{C}-\mathrm{O}$ bond defines the $S s C \stackrel{\mathrm{TS} 4}{\longleftrightarrow} A s C \stackrel{\mathrm{TS} 5}{\longleftrightarrow} S s C$ and $A a C \stackrel{\mathrm{TS} 6}{\longleftrightarrow} G^{\prime} s k^{\prime} C \stackrel{\mathrm{TS} 2}{\longleftrightarrow} G s k C \stackrel{\mathrm{TS} 7}{\longleftrightarrow} A a C$ paths. The transition state TS2, interconnecting the $G s k C$ and $G^{\prime} s k^{\prime} C$ conformers $\left(G s k C \stackrel{\text { TS2 }}{\longleftrightarrow} G^{\prime} s k^{\prime} C\right)$, corresponds to the $S a C$ conformation, with all atoms except the $\mathrm{H}$ and methyl groups connected to the $\alpha$-carbon atom in the same plane, clearly showing that the direct conversion of these conformers requires a concerted variation in both $\mathrm{C}-\mathrm{C}-\mathrm{O}-\mathrm{H}_{(\text {alcohol })}$ and $\mathrm{O}=\mathrm{C}-\mathrm{C}-\mathrm{O}$ dihedral angles.

Fig. 3 shows the approximate potential energy profiles corresponding to the different interconversion pathways relating the cis conformers, and Table 2 presents the energies of the various transition states.

The energy barrier to convert the $G^{\prime} s k^{\prime} C$ conformer into the $G s k C$ form is only $2.1 \mathrm{~kJ} \mathrm{~mol}^{-1}$ (see Fig. 3a). According to the Barnes relation, ${ }^{31}$ this barrier is low enough to be surpassed at the matrix temperature of $9 \mathrm{~K}$, and the two conformers should then exist in the matrix in equilibrium. On the other hand, at the cryogenic temperature of $9 \mathrm{~K}$, the population ratio $p_{\left(G^{\prime} s k^{\prime} \mathrm{C}\right)} / p_{(\mathrm{GskC})}$ should be equal to $\sim 6 \times 10^{-4}$ (taking into consideration the relative energy of the two conformers predicted at the DFT level and assuming the Boltzmann distribution). 
SsC

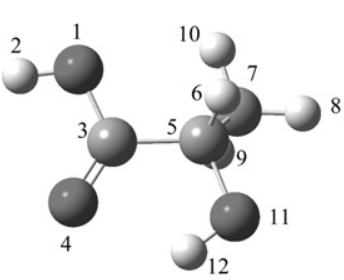

$\mathrm{O}=\mathrm{COH}:-0.2^{\circ} ; \mathrm{CCOH}: 0.3^{\circ}$ $\mathrm{O}=\mathrm{CCO}:-3.0^{\circ}$ $\mu=2.4 \mathrm{D}$
GskC

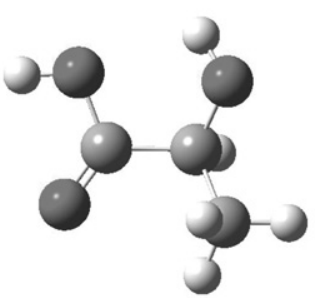

$\mathrm{O}=\mathrm{COH}:-0.3^{\circ} ; \mathrm{CCOH}: 43.3^{\circ}$ $\mathrm{O}=\mathrm{CCO}: 156.8^{\circ}$ $\mu=1.6 \mathrm{D}$
G'sk'C

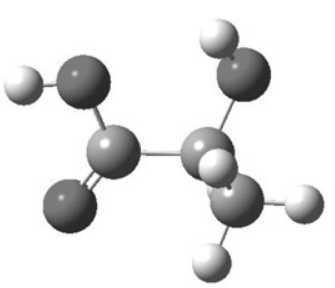

$\mathrm{O}=\mathrm{COH}: 0.4^{\circ} ; \mathrm{CCOH}:-51.5^{\circ}$ $\mathrm{O}=\mathrm{CCO}:-149.9^{\circ}$ $\mathrm{O}=\mathrm{CCO}:-149.1 \mathrm{D}$
$\mu=2.1$
AaT

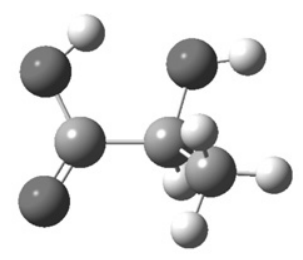

$\mathrm{O}=\mathrm{COH}:-179.3^{\circ} ; \mathrm{CCOH}: 162.2^{\circ}$ $\mathrm{O}=\mathrm{CCO}: 174.1^{\circ}$ $\mu=5.1 \mathrm{D}$
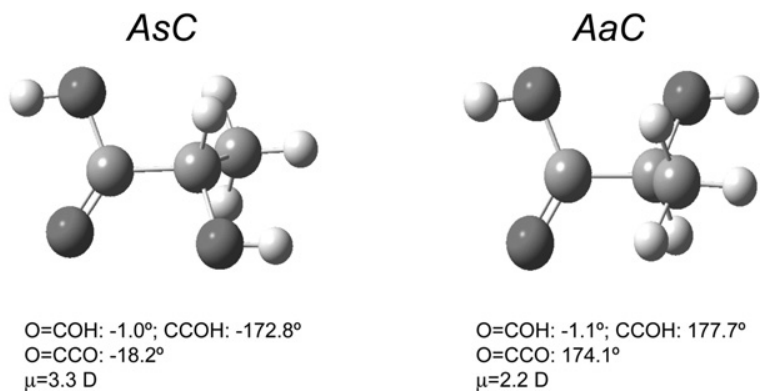

SsT

Fig. 1 Conformers of lactic acid with atom numbering scheme. For convenience, the values of the most relevant dihedral angles (degrees) and dipolar moments (Debye) are included.

Thus, we can expect to observe experimentally only the GskC form, with a population equal to the sum of the populations of these two conformers existing in the vapour before deposition. Note that an increase in the temperature of the matrix up to 40 $\mathrm{K}$ does not lead to a significant change in the $p_{\left(G^{\prime} s k^{\prime} \mathrm{C}\right)} / p_{(\mathrm{GskC})}$ population ratio, that remains smaller than $c a$. 0.1 , thus precluding the observation of the $G^{\prime} s k^{\prime} C$ form under the range of experimental conditions used in this study.

The barriers associated to the conversion $A s C \rightarrow S s C$ are of 2.1 (TS4) and 0.7 (TS5) kJ mol ${ }^{-1}$ (Fig. 3b). The latter is lower than the zero point vibrational energy associated to the $\tau \mathrm{C}$ $\mathrm{OH}_{\text {(alcohol })}$ torsion in $A s C\left(c a .1 .2 \mathrm{~kJ} \mathrm{~mol}^{-1}\right)$, and thus, in practical terms, this conformer is better described as a high energy vibrational excited state of the most stable conformer $(S s C)$. A similar situation occurs for the $A a C$ conformer relatively to $G^{\prime} s k^{\prime} C$, since the $A a C \rightarrow G^{\prime} s k^{\prime} C$ energy barrier $\left(0.8 \mathrm{~kJ} \mathrm{~mol}^{-1}\right.$; see Fig. 3d) is also lower than the zero point vibrational energy associated with the $\tau \mathrm{C}-\mathrm{OH}_{(\mathrm{alcohol})}$ torsion for this conformer (ca. $1.0 \mathrm{~kJ} \mathrm{~mol}^{-1}$ ). Hence, both $A s C$ and $A a C$ forms are not expected to be observable.

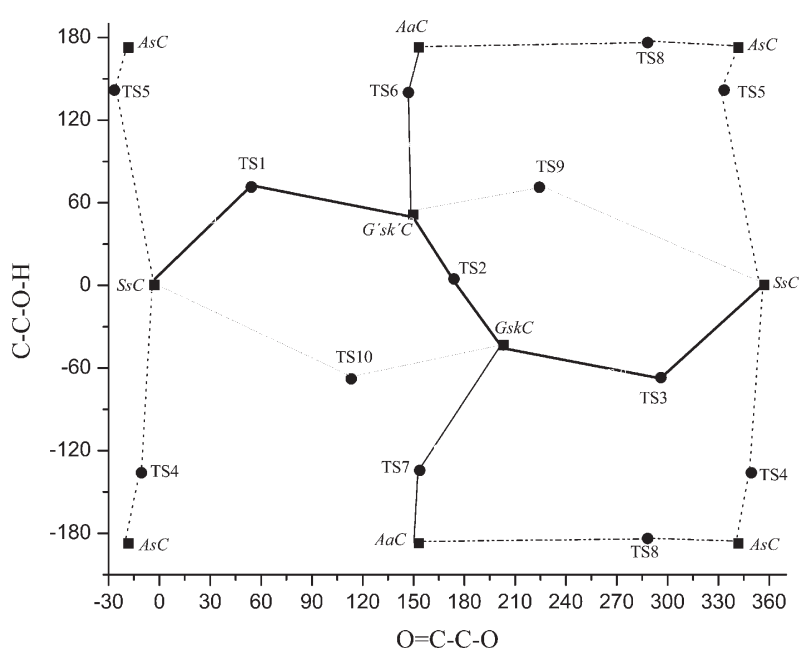

Fig. 2 Interconversion pathways among the whole set of cis conformers of lactic acid.
Summarizing, the theoretical results indicate that 3 conformers can be expected to be experimentally observed: $S s C$, whose population shall be the sum of the populations in the vapour of $S s C$ and $A s C$; $G s k C$, with a population equal to the sum of the gas phase populations of $G s k C, G^{\prime} s k^{\prime} C$ and $A a C$; and $A a T$. Conformer $S s T$ has a very high energy and is not of practical interest.

The dominant destabilizing interactions operating in the various transition states are also pointed out in Fig. 3. It is clear from the data presented in this figure (and also in Table 2) that the $\mathrm{OH}_{(\text {alcohol) }} \cdots \mathrm{H}_{3} \mathrm{C}$ repulsion, which is present in TS6 and TS5, is weaker than the $\mathrm{OH}_{(\text {alcohol })} \cdots \mathrm{HC}$ repulsion (present in TS7 and TS4), whereas the $\mathrm{CH}_{3} \cdots \mathrm{OH}_{(\text {acid) }}$ repulsion, dominating in TS1, is stronger than the $\mathrm{CH} \cdots \mathrm{OH}_{(\mathrm{acid})}$ repulsion (dominating in TS3). These results are easily understandable in simple stereochemical terms, taking into consideration the nature of the interacting groups.

\section{Vibrational spectra}

Lactic acid has 30 fundamental vibrations, all active in the infrared. Table S2 (ESI $\dagger$ ) displays the definition of symmetry coordinates used in the vibrational calculations. The calculated spectra for the experimentally relevant conformers and potential energy distributions (PED) are given in Tables S3-S5 (ESI). Vibrational assignments for lactic acid isolated in both argon and xenon matrices are displayed in Table S6 (ESI).

The infrared spectrum of lactic acid isolated in an argon matrix, at $9 \mathrm{~K}$, is presented in Fig. 4. Taking into account that at room temperature $(298 \mathrm{~K})$ the population of conformer $S_{S} C$ is $91.7 \%$, it is not surprising that the bands corresponding to conformer $S s C$ dominate the experimental spectra. The most intense bands due to the less stable conformers ( $G s k C$, which as explained previously also includes the population of $G^{\prime} s k^{\prime} C$, , and $A a T$ ), which had never been experimentally observed before, can also be observed in the spectra obtained both in argon and xenon matrices.

According to the Boltzmann distribution, the populations of these conformers are predicted to be $6.5 \%$ and $1.6 \%$ respectively (Table 1). From the relative intensities of the $\nu \mathrm{C}=\mathrm{O}$ bands assigned to each conformer, and taking into consideration the calculated intensities for these vibrations (Tables S3-S5, ESI $\dagger$ ), 

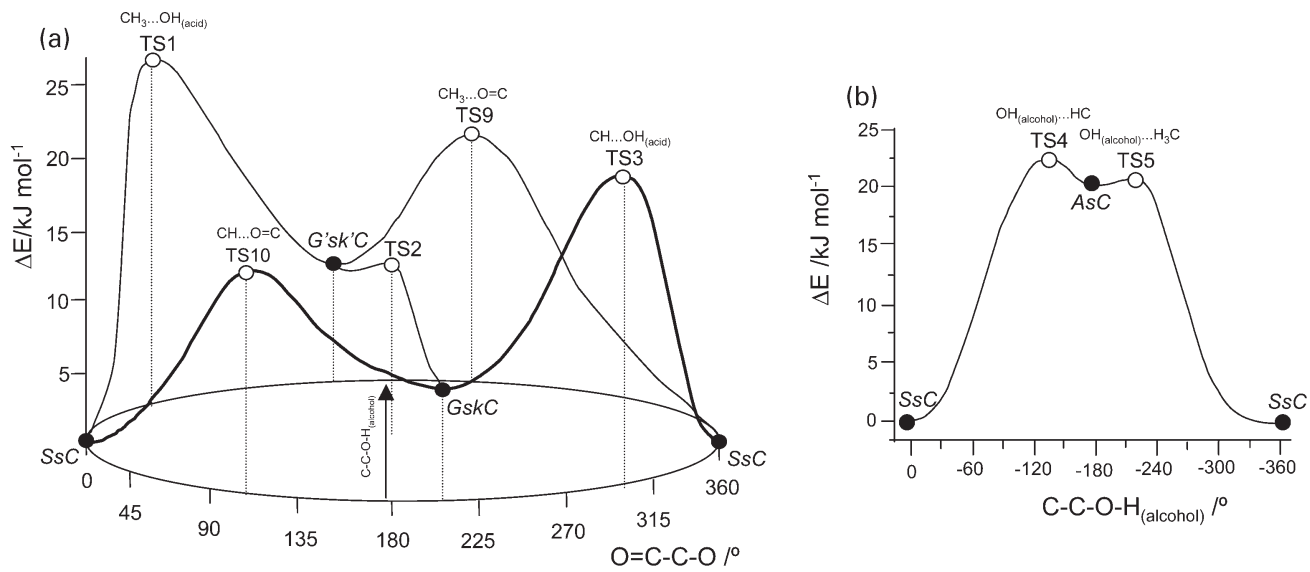

(c)
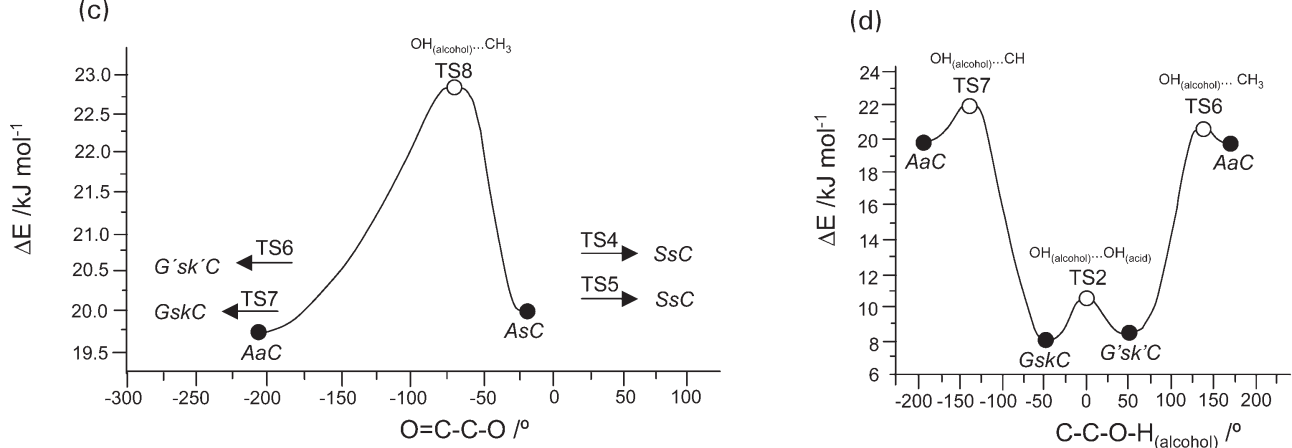

Fig. 3 DFT(B3LYP)/6-311++G(d,p) calculated potential energy profile for internal rotation around the $\mathrm{C}_{\alpha}-\mathrm{C}$ and the $\mathrm{C}-\mathrm{O}_{(\text {alcohol })}$ bonds for the following interconversions: a. $S s C \leftrightarrow G^{\prime} s k^{\prime} C \leftrightarrow G s k C \leftrightarrow S s C$, b. $S s C \leftrightarrow A s C$, c. $A s C \leftrightarrow A a C$, d. $A a C \leftrightarrow G s k C \leftrightarrow G^{\prime} s k^{\prime} C \leftrightarrow A a C$.

it was possible to estimate approximately the populations of each conformer trapped in the matrices: in argon, the $S_{s} C$ : GskC : AsT population ratio is $95.5: 3.6: 0.9 \%$; in xenon, $96.9: 2.2: 0.8 \%$. These values correlate well with the results obtained theoretically (Table 1 ).

It is important to point out that in argon matrices, the bands corresponding to the less stable conformers (especially the ones corresponding to conformer $G s k C$ ) are slightly more intense than in xenon matrices obtained in the same conditions. This fact is clearly observed, for instance, for the $\nu \mathrm{C}=\mathrm{O}, \nu \mathrm{C}-\mathrm{O}$ and $\tau \mathrm{COH}$ vibrational modes, and can be explained taking into account the better ability of argon matrices to trap the populations existing in the vapour before deposition. ${ }^{32}$

After deposition, annealing experiments were performed in both, argon and xenon matrices. After annealing in argon up to $40 \mathrm{~K}$, no conversion of the less stable conformers into conformer $S s C$ could be noticed, and only aggregation was

Table 2 DFT(B3LYP)/6-311++G(d,p) calculated relative energies $\left(\Delta E / \mathrm{kJ} \mathrm{mol}^{-1}\right)$ of the transition state structures (TSn) for interconversion between the cis conformers of lactic acid ${ }^{a}$

\begin{tabular}{|c|c|c|c|c|c|}
\hline \multicolumn{6}{|c|}{ Conformers } \\
\hline & $\mathrm{SsC}$ & GskC & $\mathrm{G}^{\prime} \mathrm{sk}^{\prime} \mathrm{C}$ & $\mathrm{AaC}$ & $\mathrm{AsC}$ \\
\hline \multirow[t]{2}{*}{$S s C$} & - & 16.4 (TS10) & 25.3 (TS1) & - & 22.2 (TS4) \\
\hline & & 18.2 (TS3) & 18.7 (TS9) & & 20.8 (TS5) \\
\hline GskC & $\begin{array}{r}8.3 \text { (TS10) } \\
\mathbf{1 0 . 2}(\text { TS } 3)\end{array}$ & - & 2.5 (TS2) & 13.8(TS7) & - \\
\hline$G s k^{\prime} C$ & $\begin{array}{l}\mathbf{1 6 . 8} \text { (TS1) } \\
\mathbf{1 0 . 2} \text { (TS9) }\end{array}$ & 2.1 (TS2) & - & 12.1 (TS6) & - \\
\hline \multirow{2}{*}{$\begin{array}{l}A a C \\
A s C\end{array}$} & - & 2.2 (TS7) & 0.8 (TS6) & - & $\mathbf{2 . 4}$ (TS8) \\
\hline & $\begin{array}{l}\mathbf{2 . 1} \text { (TS4) } \\
\mathbf{0 . 7} \text { (TS5) }\end{array}$ & - & - & 2.1 (TS8) & - \\
\hline
\end{tabular}

${ }^{a} \Delta E$ correspond to the energy barriers from the bottom of the potential energy minima. observed. The conversion $A a T \rightarrow S s C$ can be predicted not to be observable under these experimental conditions, since it requires extensive geometric rearrangements and the break of a relatively strong intramolecular $\mathrm{H}$-bond (the DFT/B3LYP calculated energy barrier for this process is $15.43 \mathrm{~kJ} \mathrm{~mol}^{-1}$ ).
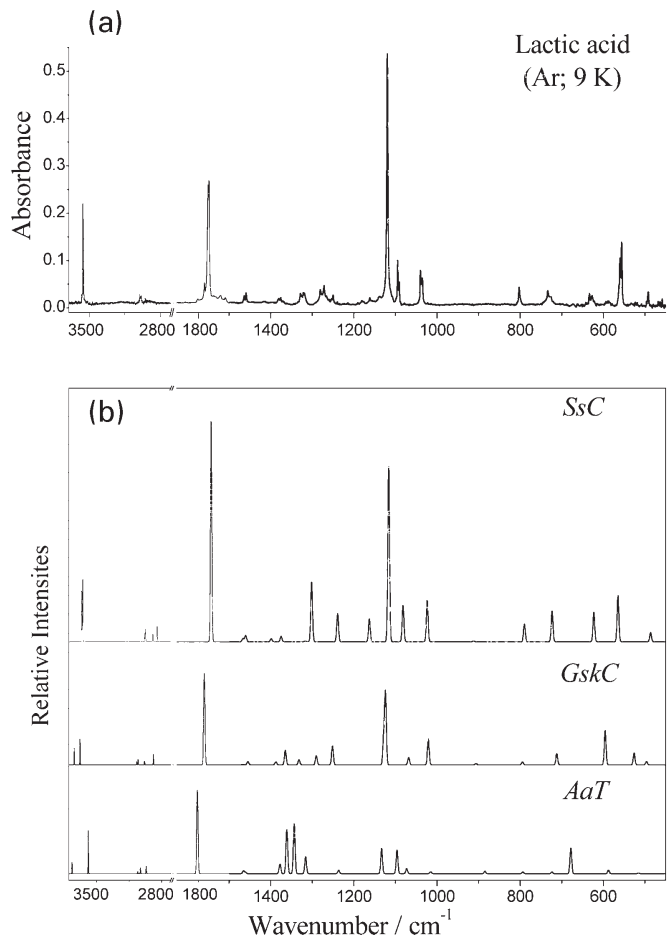

Fig. 4 Infrared spectra of lactic acid trapped in an argon matrix obtained immediately after deposition at $9 \mathrm{~K}$ (a); and calculated spectra for $A s C, G s k C$ and $A a T$ conformers, with relative intensities for each conformer shown in arbitrary units, for clarity (b). 
The $G s k C \rightarrow S s C$ conversion is much less energetic, the barrier for the process being $\sim 10 \mathrm{~kJ} \mathrm{~mol}^{-1}$ (either via TS9 or TS3; Table 2). However, according to the Barnes relationship, ${ }^{31}$ for such an energy barrier, the conversion $G s k C \rightarrow S s C$ can be expected to start only at $\sim 37 \mathrm{~K}$ and, at this temperature, aggregation was found to be important enough to prevent unequivocal observation of the putative conformational isomerization.

On the other hand, the $G s k C \rightarrow S s C$ conversion is clearly seen after annealing in xenon (Fig. 5). This fact can be explained taking into account that the annealing in xenon could be done at higher temperatures before extensive aggregation of the compound takes place (Fig. 5).

Fig. 6 depicts the infrared spectra of lactic acid trapped in argon matrices obtained using different nozzle temperatures. It can be observed from this figure that, as expected, the intensity of the bands corresponding to the less stable conformers ( GskC and $A a T$ ) increase with the temperature. According to the Boltzmann distribution, and using the relative conformational energies obtained at the DFT/B3LYP level of theory (Table 1), the populations of $S s C$ at 353 and $393 \mathrm{~K}$ can be estimated as $86.5 \%$ and $82.4 \%$ respectively). On the other hand, the populations of the less stable conformers should increase from 6.5 and $1.6 \%$ (at $298 \mathrm{~K}$ ) to 10.4 and $2.9 \%$ (at $353 \mathrm{~K}$ ) and to 13.1 and $3.9 \%$ (at $393 \mathrm{~K}$ ) for $G s k C / G^{\prime} s k^{\prime} C$ and $A a T$ respectively (Fig. 6). The relative populations of the conformers in the matrices at 353 and $393 \mathrm{~K}$, extracted from the experimental data $(\nu \mathrm{C}=\mathrm{O}$ spectral region $)$, are: $92.5,5.3$ and $2.2 \%$ and $88.9,7.8$ and $3.2 \%$ respectively, correlating fairly well with the values obtained from the Boltzmann distribution.

One additional interesting feature noticed in the spectra of lactic acid is the observation that the spectra obtained in argon show more pronounced site splitting effects. We noticed that the relative intensities of some of the bands ascribable to matrix effects varied with the amount of water present in the matrix as impurity (lactic acid is an extremely hygroscopic material and complete removal of water from the samples could never been achieved). Hence, we decided to look in deeper detail to this question, varying on purpose the amount of water in the sample. The controlled deposition of the water dopant together with the compound (within the estimated approximate range of dopant of 5-15\%), allowed us to differentiate bands corresponding to: $(a)$ the isolated lactic acid monomers, $(b)$ weakly-bound lactic acid : water complexes of each conformer of lactic acid (with probable $1: 1$ stoichiometry), and (c) higher order aggregates of these molecules. Fig. 7 displays the $\nu \mathrm{C}=\mathrm{O}$ and $\nu \mathrm{C}-\mathrm{O}$ regions, where the presence of the 3 lowest energy conformers of lactic acid can be easily recognized, as well as the bands due to the weakly-bound 1: 1 complexes associated with each one of the conformers. These observations are particularly noticeable in the case of the carbonyl stretching region, where, contrarily to the $\nu \mathrm{C}-\mathrm{O}$ spectral region, no overlap occurs between the bands due to the higher energy isolated monomers $(G s k C, A a T)$ and the bands of the aggregates. It is also important to note that the weakly-bound nature of the lactic acid : water complexes giving rise to the bands marked by the solid arrows in Fig. 7 can be easily inferred from the small deviations in the frequencies of the bands originated in these species relatively to those due to the isolated monomers.

\section{Conclusion}

Matrix-isolation FT-IR spectroscopy, supported by DFT(B3LYP)/6-311++G(d,p) and MP2 $/ 6-31++G(d, p)$ calculations allowed, for the first time, unequivocal observation and spectral signature characterization of three conformers of lactic acid.

Assignment of the observed spectra was carried out on the basis of comparison with the theoretical spectra and temperature variation data (annealing experiments in xenon and change of the nozzle temperature).

In consonance with the theoretical predictions, conformer SsC represents the most stable conformer in the gas phase, being the dominant species trapped in both, argon and xenon matrices. Also as expected taking into consideration the theoretical data, the contribution of GskC and AaT conformers to the observed spectra is small, though clearly discernable.

On the other hand, $G^{\prime} s k^{\prime} C$, could not be observed in the matrices, since this form converts quantitatively to the relatively more stable GskC conformer at the matrix temperatures, due to the very low energy barrier of interconversion between these two conformers $\left(\sim 2 \mathrm{~kJ} \mathrm{~mol}^{-1}\right)$. Annealing of the enon matrices enabled observation of the $G s k C \rightarrow S s C$ conversion.
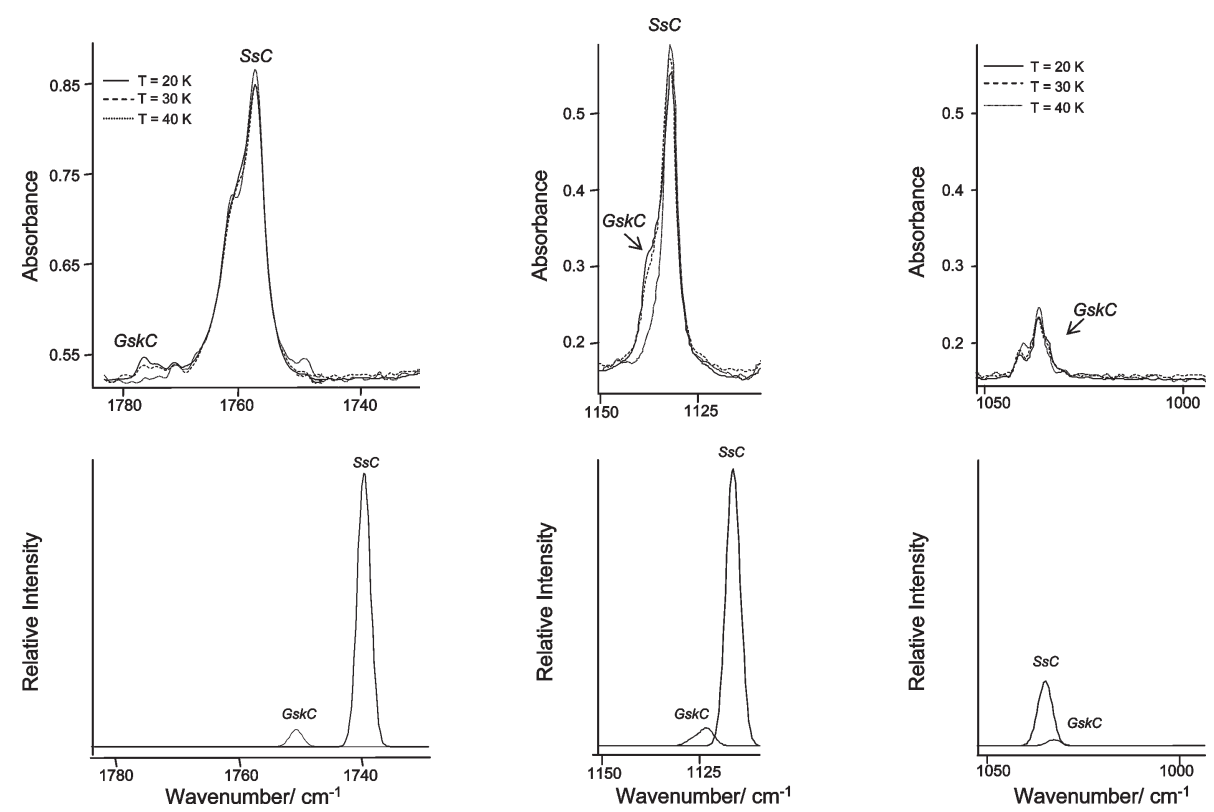

Fig. 5 Relevant spectral regions of the infrared spectrum of lactic acid trapped in a xenon matrix ( - freshly prepared sample at $20 \mathrm{~K}$; --- after annealing at $30 \mathrm{~K}$ and $\cdots 40 \mathrm{~K}$ ), and calculated spectra for $S s C, G s k C$ and $A a T$ conformers. Intensities were weighted by the calculated relative population of each conformer at $298 \mathrm{~K}$ (note that $G s k C$ total population in matrices includes also the gas phase population of $G^{\prime} s k^{\prime} C$; see text). 

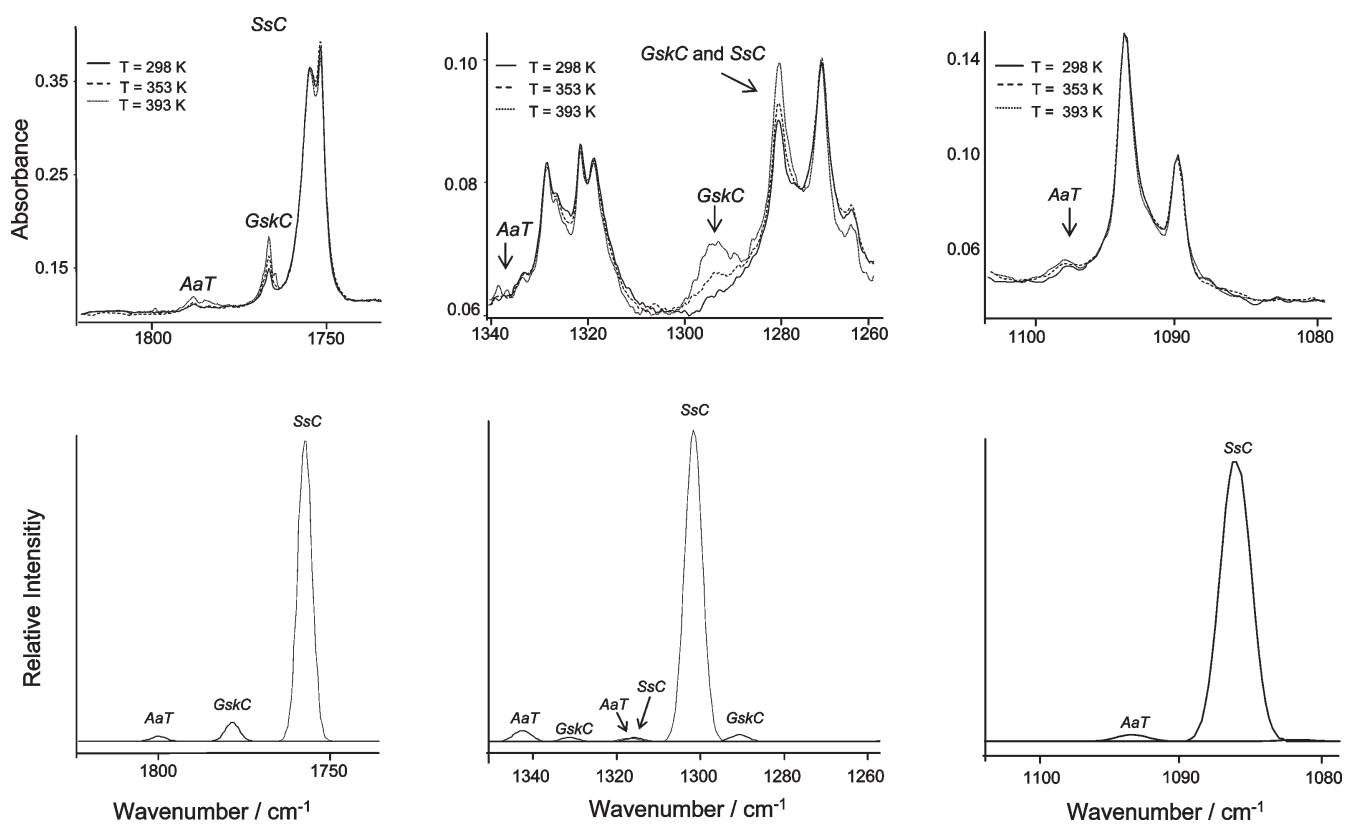

Fig. 6 Infrared spectra of lactic acid trapped in an argon matrices prepared using different nozzle temperatures $\left[T_{\text {nozzle }}=298(-), 353(---)\right.$ and $393(\ldots)$ K]. For comparison, calculated spectra are also shown. Intensities were weighted by the calculated relative population at $298 \mathrm{~K}$ (note that $G s k C$ total population includes also the gas phase population of $G^{\prime} s k^{\prime} C$; see text). As stated in Table S6, $†$ the intense calculated band of $S s C$ at 1301 $\mathrm{cm}^{-1}$ (due to $\delta \mathrm{COH}_{\text {(acid) }}$ ) is correlated with the two groups of bands found between 1328 and $1319 \mathrm{~cm}^{-1}$ and between 1281 and $1265 \mathrm{~cm}^{-1}$ that appear due to Fermi resonance (with $\nu \mathrm{CO}+\tau \mathrm{COH}_{\text {(alcohol) }}$ ) and site splitting interactions.
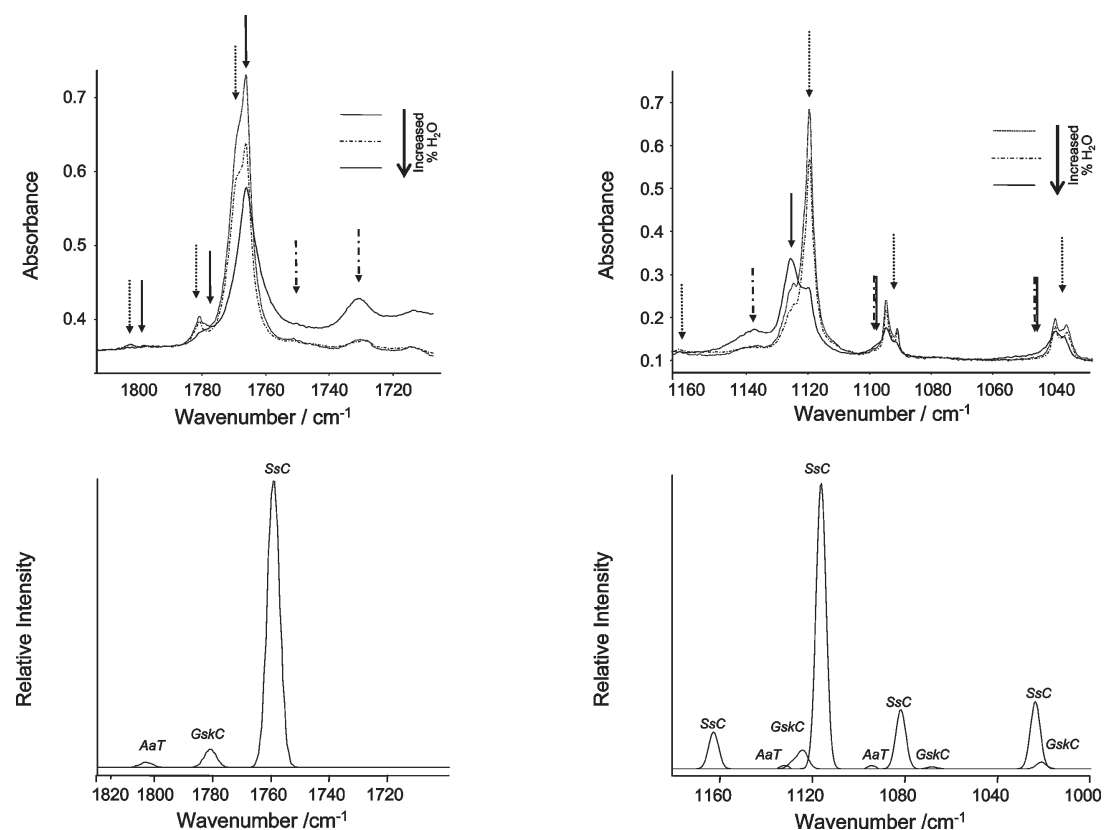

Fig. 7 Interaction of lactic acid with water dopant in an argon matrix, after deposition at $9 \mathrm{~K}$. $--\rightarrow$ point to bands due to isolated lactic acid monomers;.$- \rightarrow$ indicate bands due to the weakly-bound lactic acid : water complexes; $\rightarrow$ correspond to bands due to higher order aggregates For comparison, calculated spectra are also shown. Intensities were weighted by the calculated relative population at $298 \mathrm{~K}$ (note that GskC total population includes also the gas phase population of $G^{\prime} s k^{\prime} C$; see text).

Among the low energy conformers of lactic acid, GskC (and $G^{\prime} s k^{\prime} C$ ) might have an increased relevance in biological processes, since in these conformers the carbonyl group is more available to participate in hydrogen-bonding with the donor groups of the amino acid residues located at enzyme's active site, whereas in the conformational ground state $(S s C)$ the carbonyl group is involved in an intramolecular hydrogen bond. Notably, the conformation found in the crystal ${ }^{17}$ (similar to $A s C$, which for the isolated molecule corresponds to a high energy conformer) does have its carbonyl group free of any intramolecular H-bond.
Finally, water doping of argon matrices allowed the identification of spectral features ascribable to weakly-bound complexes of lactic acid with water.

\section{Acknowledgements}

This work was supported by the Portuguese Fundação para a Ciência e a Tecnologia (Research Project POCTI/QUI/ 43366/2001 and Grant FCT \#SFRH/BPD/11499/2002) and FEDER. 


\section{References}

1 M. Kleerebezem and J. Hugenholtz, Curr. Opin. Biotechnol., 2003, 14, 232.

2 D. Gilding and M. Reed, Polymer, 1979, 20, 1459.

3 M. Iwatsubo and C. Capeillere, Biochim. Biophys. Acta, 1967, 146, 349

4 M. Newton and G. Jeffrey, J. Am. Chem. Soc., 1977, 99, 2413

5 R. Ellison, C. Johnson and H. Levy, Acta Crystallogr., Sect. B, 1971, 27, 333.

6 W. Pijper, Acta Crystallogr., Sect. B, 1971, 27, 344.

7 C. Blom and A. Bauder, Chem. Phys. Lett., 1981, 82, 492.

8 K. Iijima, M. Kato and B. Beagley, J. Mol. Struct., 1993, 295, 289.

9 P. Godfrey, F. Rodgers and R. Brown, J. Am. Chem. Soc., 1997, 119, 2232.

10 H. Hollensein, R. Schär, G. Schwizgebel, G. Grassi and H. Günthard, Spectrochim. Acta A, 1983, 39, 193.

11 H. Hollenstein, T. Ha and H. Günthard, J. Mol. Struct. (Theochem), 1986, 146, 289.

12 F. Jensen, Acta Chem. Scand., 1997, 51, 439.

13 H. Hasegawa, O. Ohashi and I. Yamaguchi, J. Mol. Struct., 1982, 82, 205.

14 C. Blom and A. Bauder, J. Am. Chem. Soc., 1982, 104, 2993.

15 S. Jarmelo and R. Fausto, Phys. Chem. Chem. Phys., 2002, 4, 1555.

16 W. Gaykema, J. Kanters and G. Roelofsen, Cryst. Struct. Commun., 1978, 7, 463.

17 A. Shouten, J. Kanters and J. van Krieken, J. Mol. Struct., 1994, 323, 165 .

18 G. Cassanas, M. Morssli, E. Fabregue and L. Bardet, J. Raman Spectrosc., 1991, 22, 409 .
19 G. Cassanas, G. Kister, E. Fabrègue, M. Morssli and L. Bardet, Spectrochim. Acta A, 1993, 49, 271.

20 B. van Eijck, J. Mol. Spectrosc., 1983, 101, 133.

21 M. Pecul, A. Rizzo and J. Leszczynski, J. Phys. Chem. A, 2002, 106, 11008.

22 M. Frisch, G. Trucks, H. Schlegel, G. Scuseria, M. Robb, J. Cheeseman, V. Zakrzewski, J. Montgomery, R. Stratmann, K. Burant, S. Dapprich, J. Millam, A. Daniels, K. Kudin, M. Strain, O. Farkas, J. Tomasi, V. Barone, M. Cossi, R. Cammi, B Mennucci, C. Pomelli, C. Adamo, S. Clifford, J. Ochterski, G. Petersson, P. Ayala, Q. Cui, K. Morokuma, D. Malick, A. Rabuck, K. Raghavachari, J. Foresman, J. Cioslowski, J. Ortiz, A. Baboul, B. Stefanov, G. Liu, A. Liashenko, P. Piskorz, I. Komaromi, R. Gomperts, R. Martin, D. Fox, T. Keith, M. Al-Laham, C. Peng, A. Nanayakkara, M. Challacombe, P. Gill, B. Johnson, W. Chen, M. Wong, J. Andres, C. Gonzalez, M. Head-Gordon, S. Replogle and J. Pople, Gaussian 98, revision A.9, Gaussian Inc., Pittsburgh, PA, 1998.

23 M. Frisch, M. Head-Gordon and J. Pople, Chem. Phys. Lett. 1990, 166, 281.

24 A. Becke, Phys. Rev. A, 1988, 38, 3098.

25 C. Lee, W. Yang and R. Parr, Phys. Rev. B., 1988, 37, 785

26 S. Vosko, L. Wilk and M. Nusair, Can. J. Phys., 1980, 58, 200.

27 P. Csaszar and P. Pulay, J Mol. Struct. (Theochem), 1984, 114, 31 .

28 J. Schachtschneider, Technical Report, Shell Development Co. Emeryville, CA, 1969.

29 C. Peng and H. Schlegel, Isr. J. Chem., 1994, 33, 449.

30 I. Reva, S. Stepanian, L. Adamowicz and R. Fausto, J. Phys. Chem. A., 2001, 105, 4773.

31 A. Barnes, J. Mol. Struct., 1984, 113, 161.

32 I. Reva, S. Stepanian, L. Adamowicz and R. Fausto, Chem. Phys Lett., 2003, 374, 631 . 